\title{
A Simple Stereophotographic Technique for Analyzing Small Plots
}

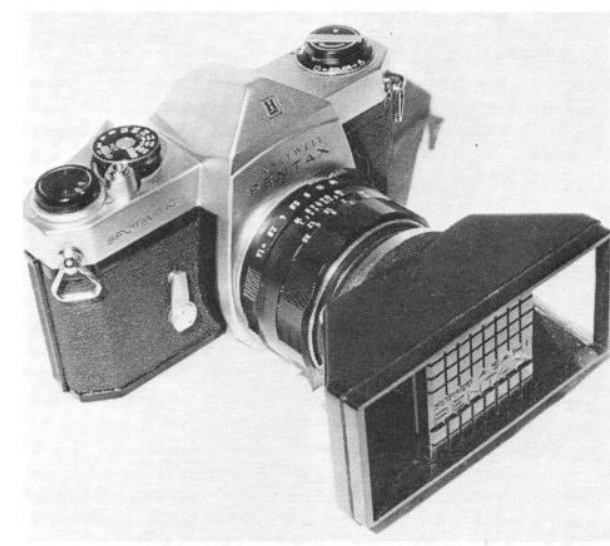

Fig. 1. Camera with stereo adapter attached.

\section{RAYMOND D. RATLIFF AND STANLEY E. WESTFALL}

Highlight: An inexpensive stereo adapter for a camera provided stereo pairs on a single color print. At a camera height of 48 inches, we obtained good resolution of a square-foot area and a scale of 1:7. The stereo prints are used with a dot grid overlay and a pocket stereoscope to estimate foliar cover and composition.

During a study of back country meadows in the central Sierra Nevada Mountains of California, we needed information on foliar cover and composition. Travel in this high country was by helicopter and on foot and, therefore, expensive. We had much ground to cover and a limited budget. Hence, we needed a method of gathering these data which would reduce field time--even at the expense of increasing office time.

Review of the literature had indicated that stereophotographs would do the job. However, equipment similar to that described by Pierce and Eddleman (1970) or Wells (1971) appeared too cumbersome for packing up and down steep mountain trails.

Instead, we used a Honeywell Pentax ${ }^{1}$ $35 \mathrm{~mm}$ single-lens reflex camera with a stereo adapter of the same make (Fig. 1). The adapter splits the $24-\mathrm{mm}$ by $36-\mathrm{mm}$ format into a stereo pair of single-frame images. If Kodacolor X film is used, the stereo pairs come from the processor on one print (Fig. 2) and can be easily viewed with a pocket stereoscope. Hence, we decided to use prints rather than slides.

Because a standard format and scale

The authors are range ecologist and range technician, Pacific Southwest Forest and Range Experiment Station, Forest Service, U. S. Department of Agriculture at Berkeley, California. The authors are stationed at Fresno.

Manuscript received July 20, 1972.

\footnotetext{
${ }^{1}$ Trade names and commercial enterprises or products are mentioned solely for information. No endorsement by the U. S. Dep. Agr. is
} implied. foliar cover and composition, we devised a simple "photo frame" (Fig. 3). The upright portion, bent out of $1 / 2$-inch electrical conduit, was made to set up a camera height of 48 inches. We had found that this height produced good resolution of the vegetation on a square-foot area, and that standard 3-1/2-inch by 5 -inch prints gave a scale of about 1:7.

The base of the photo frame was made to slip over a square-foot sampling frame. The photographer could thus leave a sampling frame in place for clipping and move to the next location. This arrangement permitted herbage yield as well as were required for later assessment of foliar cover and composition to be determined for each plot. In addition, a slate with a plot code was photographed with each plot, providing positive identification of each print.

We are using the stereo prints with a dot grid overlay and a pocket stereoscope to estimate foliar cover and composition. Generally, individual species can be identified, but a familiarity with the species comprising the vegetation type is a necessity.

Using a single camera with a stereo adapter has several advantages over techniques now in common use. The stereo adapter ends off-setting for a second picture and only costs about \$30-much less than a second camera. As with two

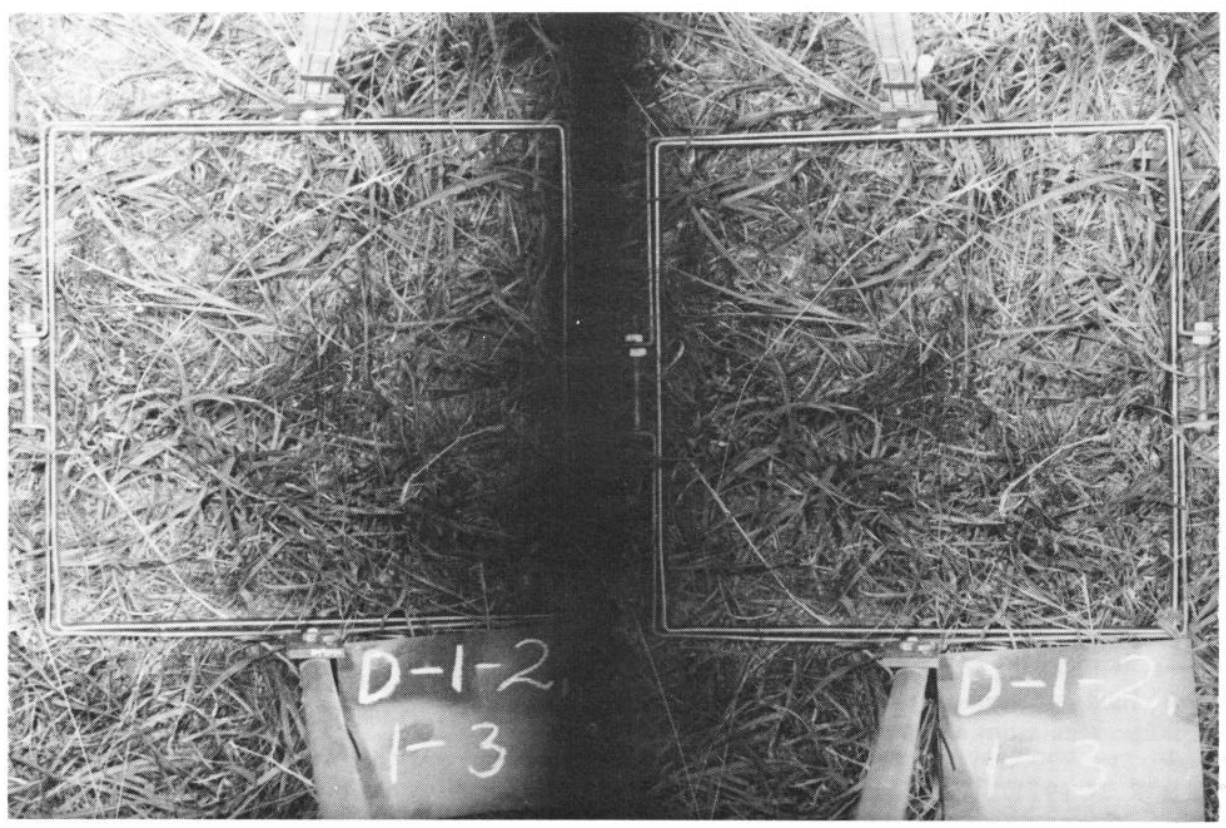

Fig. 2. Color prints 31/2- by 5-inch provide good resolution and can be viewed in stereo with a pocket stereoscope. 


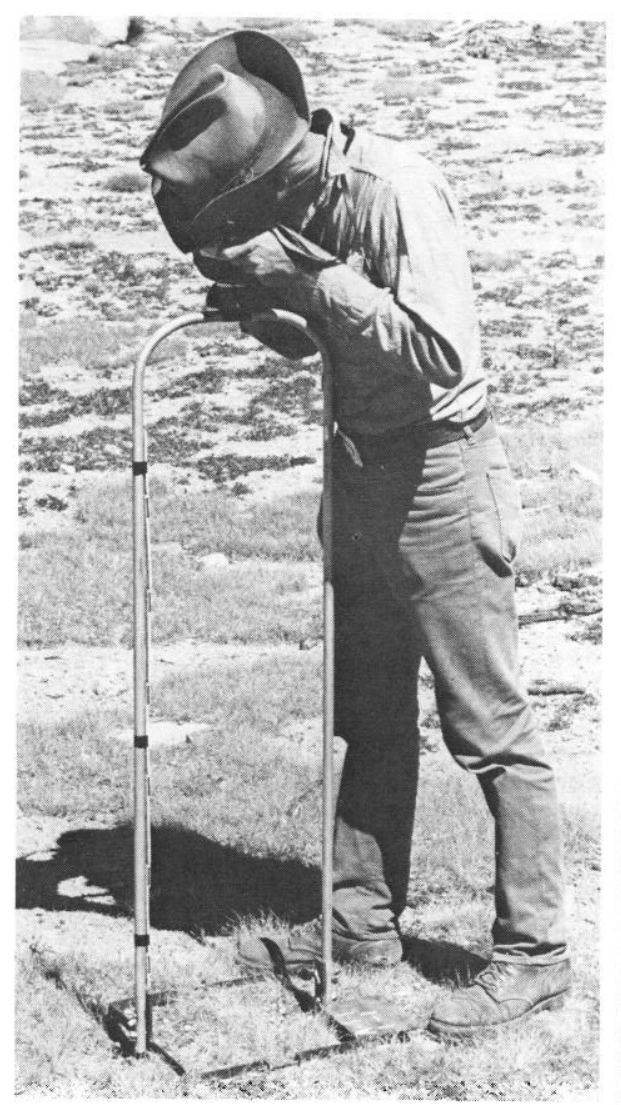

Fig. 3. A photo frame is used to obtain a stereo photo of a square foot plot.

cameras triggered simultaneously, problems with wind or clouds or both producing somewhat different images are avoided. But if only one camera must be focused, equal depth of field on the stereo pair is assured. Because the stereo pair is produced on one print or slide rather than two, total costs for film, developing, and printing are reduced. Furthermore, problems of matching up stereo pairs, as is necessary with separate print methods, are eliminated.

We have not yet tested this stereophotographic technique for quadrates larger than a square foot. We do know that a greater camera height would be required. The scale would therefore be smaller and species identification perhaps more difficult. However, the technique is a valuable tool where small plots will suffice and in situations in which use of more sophisticated equipment is impractical.

\section{Literature Cited}

Pierce, William R., and Lee E. Eddleman. 1970. A field stereophotographic technique for range vegetation analysis. J. Range Manage. 23:218-220.

Wells, K. F. 1971. Measuring vegetation changes on fixed quadrates by vertical ground stereophotography. J. Range Manage. $24: 233-236$. 